\title{
“iNo mueras, te amo tanto! Pero el cadáver jay! siguió muriendo"(*): Protecciones específicas, muerte, duelo y derechos humanos en el contexto pandémico ${ }^{(* *)}$
}

\author{
"Do not die, I love you so much! But the corpse, alas! kept on dying": Specific \\ protections, death, bereavement and human rights in the pandemic context
}

\author{
Piero Vásquez Agüero( ${ }^{(* *)}$ \\ Pontificia Universidad Católica del Perú (Lima, Perú)
}

Resumen: El presente artículo busca responder la pregunta de cuál ha sido la respuesta del derecho internacional de los derechos humanos y los órganos internacionales de protección a los derechos humanos en la fijación de lineamientos para los Estados frente al fenómeno de la pandemia por COVID-19. El texto plantea que la alta adaptabilidad de las normas de protección del ser humano y los estándares desarrollados en la materia han podido desplegar sus efectos protectores en relación con i) los límites de la adopción de restricciones o suspensiones de derechos humanos para el control epidémico y ii) las disposiciones específicas para el resguardo de los grupos vulnerables. Hacia el final del texto, por la importancia de la materia en el marco de la pandemia, el autor se detiene para referirse de modo específico a la aproximación del derecho internacional de los derechos humanos hacia la muerte, el manejo de cadáveres, el duelo y la participación de las familias en las decisiones sobre la disposición de los cuerpos de sus seres queridos.

\begin{abstract}
This article seeks to explore the response of international human rights law and international human rights bodies in the definition of guidelines for States to tackle the COVID-19 pandemic. The main argument is that the high levels of adaptability of the norms for the protection of human beings and the standards developed in this matter are reflected in the way their protective effects have been at display; mainly, in i) the limits for restrictions or suspensions of human rights for epidemic control and ii) the specific provisions for the protection of vulnerable groups. Towards the end of the document, given the importance of the subject in the context of the pandemic, the author reflects on the approach of international human rights law towards death, the handling of corpses, the mourning and the participation of families in decisions regarding the disposition of the bodies of their loved ones.
\end{abstract}

Palabras clave: Derecho Internacional de Derechos Humanos - Covid-19 - Grupos en situación de vulnerabilidad - Perú - Protección de Derechos Humanos

Keywords: International Human Rights Law - Covid-19 - Groups in vulnerable situations - Peru - Protection of Human Rights

$\left(^{*}\right) \quad$ Fragmento del poema "Masa" de César Vallejo escrito en 1937.

${ }^{(*)} \quad$ Nota del Editor: Este artículo fue recibido el 24 de septiembre de 2020 y su publicación fue aprobada el 8 de noviembre de 2020.

${ }^{* * *}$ Abogado y magíster en derechos humanos por la PUCP y estudiante del Doctorado en Derecho por el Instituto de Investigaciones Jurídicas de la UNAM. Abogado consultor de la Comisión Interamericana de Derechos Humanos y profesor de Derechos Humanos en la Facultad de Derecho de la PUCP. ORCID: https://orcid.org/0000-0001-8986-9885. Correo electrónico: piero.vasquez@pucp.pe 
“¡No mueras, te amo tanto! Pero el cadáver ¡ay! siguió muriendo” : Protecciones específicas, muerte, duelo y derechos humanos en el contexto pandémico

"Do not die, I love you so much! But the corpse, alas! kept on dying": Specific protections, death, bereavement and human rights in the pandemic context

\section{Introducción}

Tan solo el año pasado, en el discurso presidencial de 28 de julio de 2019, el presidente Martín Vizcarra anunciaba la llegada del seguro médico universal en el Perú. En ese momento, la idea de incorporar a 4 millones de peruanos y peruanas que no gozaban de ningún tipo de cobertura en salud no solo sonaba como una buena política de Estado, sino que representaba un esfuerzo enorme en un sistema de salud como el peruano y generaba una expectativa positiva en el desarrollo progresivo de un derecho tantas veces postergado, como el derecho a la salud (PAHO, 2019).

El Decreto de Urgencia que establecía las medidas para la cobertura universal fue adoptado el 28 de noviembre de 2019, y no se había terminado de celebrar cuando, poco tiempo después, llegó el virus SARS-CoV2 al Perú con sus terribles efectos multidimensionales. Tal como el presidente Vizcarra ha calificado "no es solamente una crisis de salud, es una crisis social y económica sin precedentes" (New York Times, 2020). Para noviembre de 2020, en el Perú, cerca de 35 mil personas habían fallecido a causa de la pandemia, es decir, casi la mitad de las muertes que dejó el conflicto armado peruano ocurrido entre 1980 y el año 2000 (CVR, 2003).

Asimismo, esta realidad ha obligado a los tomadores de decisión a no voltear más la mirada respecto de la prestación de los servicios de salud y la infraestructura hospitalaria en el Perú. Como señala el doctor Maguiña "esta nueva enfermedad (COVID-19), ha desnudado de manera cruda y real, la terrible situación sanitaria del Perú: hospitales viejos, falta de materiales, laboratorios especializados, camas, ventiladores, especialistas, y una población geriátrica abandonada, médicos mal remunerados, sin seguro médico, y como nunca, falta de equipos de bioseguridad para combatir a este nuevo flagelo" (2020). Sobre este mismo tema, la Defensoría del Pueblo también se ha referido a los conflictos sociales de índole laboral del personal médico y sanitario, cuya posición en la primera línea de atención de las personas infectadas resulta fundamental, respecto de demandas relacionadas con su acceso a equipos de protección para la prestación del servicio de salud y ajustes en sus remuneraciones (2020, p. 13).

En este contexto de película sobre una realidad distópica, consideramos que las respuestas y el análisis de los cursos de acción para abordar la problemática de la pandemia deben provenir desde las diferentes ramas del conocimiento. En estos términos, el presente artículo busca dilucidar cuál ha sido la respuesta de los órganos internacionales de protección de los derechos humanos para brindar orientaciones a los Estados para el desarrollo de políticas de control pandémico con enfoque de derechos humanos. Así, desde el punto de vista del derecho internacional derechos humanos (en adelante "el DIDH") es posible advertir diversos ejercicios de interpretación realizados por órganos internacionales con mandatos de protección de derechos humanos para brindar cobertura a las nuevas situaciones desatadas por la pandemia.

A continuación, se realizará un rastreo e identificación de la aplicación y salvaguardas realizadas por los órganos de protección de derechos humanos, con énfasis en los órganos del sistema interamericano y siempre con una mirada desde la realidad peruana. Asimismo, hacia el final de este artículo se profundizará respecto de la regulación y jurisprudencia relacionada con la muerte, el manejo de cadáveres, la participación de familiares en las decisiones sobre sus seres queridos, con la intención de demostrar la aplicabilidad de dichos desarrollos normativos, al menos en cierta medida, es posible de cara a la pandemia.

\section{La pandemia de CoVID-19 como un problema de derechos humanos y la respuesta del DIDH}

A continuación, apuntaremos algunos aspectos que demuestran y confirman que la pandemia, es una crisis de derechos humanos, y que el DIDH, pese a no contener prescripciones específicas relacionadas con su manejo, ha brindado cobertura y límites a los fenómenos relacionados con las restricciones de derechos humanos en el control pandémico.

2.1. Principales restricciones $y$ afectaciones a los derechos humanos en el marco de la pandemia

Con el inicio de las primeras decisiones estatales para la regulación epidémica, la reacción inicial de los Estados, incluido el Perú, tuvo un corte eminentemente restrictivo. En la región americana la respuesta ha sido variada, desde el establecimiento de cuarentenas voluntarias o restricciones específicas sobre la movilidad, como en México y Estados Unidos, hasta la declaratoria de estados de emergencia como en los casos de Perú y Colombia.

En el Perú, la declaratoria de estado de emergencia se dio el 15 de marzo de 2020 a 
través de un Decreto Supremo que justificaba la medida por las "graves circunstancias que afectan la vida de la Nación a consecuencia del brote del COVID-19" (DS-044-2020PCM). La declaratoria de estado de emergencia se emitió en concordancia con lo establecido en el artículo 137.1 de la Constitución Política de 1993, que establece que "en esta eventualidad, puede restringirse o suspenderse el ejercicio de los derechos constitucionales relativos a la libertad y la seguridad personales, la inviolabilidad de domicilio, y la libertad de reunión y de tránsito en el territorio". Asimismo, el Decreto también estableció la participación de las fuerzas armadas y policiales en el cumplimiento de las tareas de control epidémico.

Si bien esta primera medida fue aprobada por 15 días, posteriormente ha sido modificada y ampliado su plazo en múltiples oportunidades, hasta la emisión del Decreto Supremo 116-2020-PCM que prorrogó el estado de emergencia, pero introdujo la llamada "cuarentena focalizada" de cara al establecimiento de la "Nueva Convivencia Social", flexibilizando las medidas de aislamiento e inmovilización social obligatoria. Al mencionado Decreto, le sucedió el Decreto Supremo 1462020-PCM, que vuelve a prorrogar el estado de emergencia, reiterando la restricción de derecho en los mismos términos constitucionales, aunque manteniendo una tendencia hacia la flexibilización a través de la cuarentena focalizada.

Ahora bien, es importante enfatizar lo extremo que resulta una declaratoria de estado de emergencia, más allá de la necesaria de su activación. Lovatón describió correctamente que "esta pandemia y las medidas restrictivas adoptadas, han sumado más precariedad, sufrimiento y hambre a millones de compatriotas latinoamericanos" (Lovatón, 2020). Por otro parte, la innegable transformación de la vida cotidiana de las personas en el contexto de la pandemia ocurre "en la medida que el ejercicio de nuestros derechos no solo de libertad personal, sino también los sociales, se han visto limitados y restringidos por la decisión de las autoridades, así como por la acción de las fuerzas policiales y militares" (Landa, 2020, p. 17).

Diferente a una crisis política o una crisis económica, esta crisis sanitaria reconfiguró la realidad de las personas habitantes en el Perú de un modo radical e inmediato, con efectos constatables y prologados en la vida diaria. Para el DIDH, esta transformación sustancial, debe levantar las máximas alertas, pues en esta clase de situaciones de alta volatilidad social, es cuando la línea entre las restricciones válidas de los derechos humanos y la arbitrariedad pueden verse fácilmente confundidas, y la orientación a la represión se mal transforma en un derecho a castigar, en el que el ciudadano se convierte en enemigo, porque el "enemigo es el que no obedece" (Aniyar de Castro, 1989, p. 62).

Como el Tribunal Constitucional ha reconocido, los estados de emergencia suponen una situación que impide el funcionamiento de la denominada "normalidad constitucional"
(TC, 2004, párrafo 10) caracterizado por una concentración inusual del poder en el poder ejecutivo y el correlativo acrecentamiento de las atribuciones de las fuerzas policiales y militares (TC, 2004, párrafo 15.a). Ante esta situación, en los estados de emergencia, el DIDH no se vuelve un derecho complaciente o inaplicable, sino que agrega una capa adicional de protección o filtro de control para equilibrar el descrito desbalance cuando ocurren restricciones aceleradas o excepcionales de los derechos humanos de cara a las obligaciones internacionales asumidas por los Estados en esta materia, con especial relevancia frente al histórico abuso de esta figura en los países de la región americana (Faúndez, 2004, p. 96).

La Convención Americana sobre Derechos Humanos (en adelante "la Convención Americana" o "la CADH") regula la situación jurídica de los estados de excepción en su artículo 27, estableciendo las causales procedentes para la suspensión de garantías e indicando el núcleo de derechos que no pueden ser suspendidos, entre los que se encuentran el derecho al reconocimiento de la personalidad jurídicas, derecho a la vida, el derecho a la integridad, personal, la prohibición de la esclavitud, principio de legalidad y retroactividad, libertad de conciencia y religión protección a la familia, derecho al nombre, derechos del niño, derecho a la nacionalidad y derechos políticos, y las garantías judiciales, incluidos el habeas corpus y el proceso de amparo, así como los recursos judiciales idóneos para la defensa de los derechos que no se encuentran suspendidos (Corte IDH, 1987). Adicionalmente, el artículo 27 también dispone que la "suspensión de garantías" debe comunicarse al resto de estados parte de la CADH, a través de la Secretaría General de la Organización de Estados Americanos (en adelante "la OEA").

En un escenario tan delicado y ante una posible lectura en la que se presuma que los derechos son inexistentes o que el gobierno está "investido de poderes absolutos o más allá de los estrictamente necesarios" (Curaca, 2020, p. 31) la Comisión Interamericana de Derechos Humanos (en adelante "la CIDH", "la Comisión Interamericana" o "la Comisión"), 
“¡No mueras, te amo tanto! Pero el cadáver ¡ay! siguió muriendo” : Protecciones específicas, muerte, duelo y derechos humanos en el contexto pandémico

"Do not die, I love you so much! But the corpse, alas! kept on dying": Specific protections, death, bereavement and human rights in the pandemic context

emitió la Resolución 1/2020 "Pandemia y Derechos Humanos en las Américas" que, desde nuestro punto de vista, ordenó el debate: las medidas adoptadas por los Estados en la atención y contención del virus deben tener como centro el pleno respeto de los derechos humanos (CIDH, 2020).

En la mencionada Resolución 1/2020, la CIDH indicó que, durante la vigencia de los estados de excepción y las medidas restrictivas, los otros poderes del Estado mantienen un "rol fundamental" cuyo funcionamiento debe ser asegurado para resguardo de los sistemas democráticos. Asimismo, la $\mathrm{CIDH}$ alzó la voz, respecto de una situación ausente que los decretos que establecieron las restricciones de la pandemia no apuntaron de modo explícito: el impacto desproporcional de las medidas de control pandémico sobre determinados grupos (p. 6).

En efecto, en términos de aplicación, los impactos de las medidas restrictivas devenidas del estado de emergencia, en un país como Perú, no es simplemente una operación jurídica que pueda reputarse neutral. La profunda desigualdad que aqueja a los peruanos y peruanas obliga al Estado a presentar alternativas que permitan contrarrestar los efectos (¿discriminatorios?) indirectos que estas medidas puedan generar en grupos en situación de vulnerabilidad.

En estos términos, en el marco del control de la epidemia, se trate de una situación de restricción específica de derechos o de la restricción general del artículo 27 de la Convención Americana, el DIDH establece requisitos, además de los estipulados en el derecho interno, para salvaguardar a las personas de actos de arbitrariedad. Así, tratándose de una restricción específica de un determinado derecho fundamental, esta tendrá que cumplir con el "principio de legalidad, ser necesarias en una sociedad democrática y, por ende, resultar estrictamente proporcionales para atender la finalidad legítima de proteger la salud" (CIDH, párrafo 20).

De otro lado, como en el caso del Perú, si la restricción es de tipo general, debe cumplir con el artículo 27 de la Convención Americana, en los términos analizados por la Corte Interamericana de Derechos Humanos (en adelante "la Corte IDH", "la Corte Interamericana" o "la Corte") en su Opinión Consultiva OC-8/87 (Corte IDH, 1987, párrafos 37-44). Los estándares anteriormente mencionados fueron expresados por la CIDH del siguiente modo, de cara a la emergencia sanitaria, para determinar la validez de una restricción adecuada en un estado de emergencia:

(i) [que] se justifique que existe una excepcionalidad de la situación de emergencia en cuanto a su gravedad, inminencia e intensidad que constituye una amenaza real a la independencia o seguridad del Estado;

(ii) [que] la suspensión de algunos derechos y garantías sea únicamente por el tiempo estrictamente limitado a las exigencias de la situación; (iii) [que] las disposiciones que sean adoptadas resulten proporcionales, en particular, que la suspensión de derechos o garantías constituya el único medio para hacer frente a la situación, que no pueda ser enfrentada mediante el uso de las atribuciones ordinarias de las autoridades estatales, y que las medidas adoptadas no generen una mayor afectación al derecho que sea suspendido en comparación con el beneficio obtenido; y

(iv) [que] las disposiciones adoptadas no sean incompatibles con las demás obligaciones que impone el derecho internacional, y no entrañen discriminación alguna fundada, en particular, con motivos de raza, color, sexo, idioma, religión u origen social.

Sumado a todo lo anterior, la Comisión y la Corte han señalado que es necesario que las decisiones restrictivas se adopten conforme a criterios científicos y tomando en consideración el impacto diferenciado en las poblaciones vulnerables (CIDH, 2020, párrafo 27). En el siguiente apartado se analizarán las afectaciones de derechos humanos de los grupos en situación de vulnerabilidad en el contexto de la pandemia por COVID-19.

\subsection{Grupos en situación de vulnerabilidad y pandemia}

Esta es la primera vez que el sistema regional de protección de derechos humanos debe atender una situación de pandemia. Siendo esta la situación, los estándares interamericanos para la protección de derechos humanos no estaban explícitamente adecuados a esta nueva disruptiva realidad. Al revisar la Convención Americana, no encontraremos ninguna referencia a la aplicación de los derechos humanos en contextos de pandemia. Sin embargo, desde nuestro punto, las normas de derechos humanos tienen una profunda vocación de adaptabilidad y son altamente resilientes, dado que, por su formulación, permite su acomodo contextual de modo más concreto. Si partimos de la premisa de que todo texto legal requiere ser interpretado (Helmersen, 2013, p. 164), es fácilmente distinguible que los órganos de protección de derechos humanos, recurren constantemente a la interpretación evolutiva para aplicar las normas cuyos 
mandatos les han encargado interpretar (Sonnleitner, 2019, p. 285; Salmón, 2014, p. 215), bajo la premisa de que realizan esta labor hermenéutica sin desnaturalizar la propia norma cuyo contenido corresponde aplicar, incluso en realidades fácticas no habituales.

\subsubsection{La determinación de grupos vulnerables desde el DIDH} Tanto la CIDH como la Corte IDH han apuntado al fenómeno del impacto diferenciado de las medidas para el control epidémico sobre grupos en situación de vulnerabilidad. Ahora bien, el listado de "grupos en situación de vulnerabilidad" ha ido variando a lo largo del tiempo en el marco del sistema interamericano (García Ramírez, 2019; Valdivia, 2020); por lo que más allá de los grupos que lo componen, García Ramírez (2019) apunta a una definición desde el derecho a la igualdad que permite entender la necesidad de establecer protecciones especiales "(...) existen factores de hecho -y también, en su hora y circunstancia, de derecho- que plantean obstáculos de mayor o menor entidad para el verdadero disfrute de esos derechos. Ello obliga a establecer, a título de matiz o complemento del principio de igualdad -o factor para el efectivo imperio de éste-, un principio de signo característico: principio de "especificidad", que opera como factor de igualación de los titulares de derechos, naturalmente desiguales, a través de distintos medios acogidos por el orden nacional e internacional en calidad de protecciones especiales" (p. 8) (notas omitidas).

Cuadro 1: grupos en situación de vulnerabilidad reconocidos por órganos del sistema interamericano en el contexto de la pandemia

\begin{tabular}{|l|c|c|}
\hline Grupo en situación de vulnerabilidad & Corte IDH & $\mathrm{CIDH}$ \\
\hline Personas mayores & $\mathrm{X}$ & $\mathrm{X}$ \\
\hline Niños, niñas y adolescentes & $\mathrm{X}$ & $\mathrm{X}$ \\
\hline Personas con discapacidad & $\mathrm{X}$ & $\mathrm{X}$ \\
\hline Personas migrantes, refugiados y apátridas & $\mathrm{X}$ & $\mathrm{X}$ \\
\hline Personas privadas de libertad & $\mathrm{X}$ & $\mathrm{X}$ \\
\hline Personas LGTBI & $\mathrm{X}$ & $\mathrm{X}$ \\
\hline Mujeres embarazadas o período postparto & $\mathrm{X}$ & $\mathrm{X}$ \\
\hline Comunidades indígenas & $\mathrm{X}$ & $\mathrm{X}$ \\
\hline Personas afrodescendientes & $\mathrm{X}$ & $\mathrm{X}$ \\
\hline Personas que viven del trabajo informal & $\mathrm{X}$ & \\
\hline Personas de habitación precaria & $\mathrm{X}$ & \\
\hline Personas en situación de calle & $\mathrm{X}$ & \\
\hline Personas en situación de pobreza & $\mathrm{X}$ & \\
\hline Personal de salud que atiende emergencias & $\mathrm{X}$ & \\
\hline Personas víctimas de trata de personas & & $\mathrm{X}$ \\
\hline Personas desplazadas internas & & $\mathrm{X}$ \\
\hline Personas con COVID-19 & $\mathrm{X}$ \\
\hline
\end{tabular}

Sumado a lo anterior, Valdivia apunta a que el principio de no discriminación requiere actualizar su contenido de modo que "su eficacia como herramienta para el develamiento de diferenciaciones injustas no se vea mermada" (2020, p. 10). En este entendido, según el análisis de la autora, las jurisprudencias de la Corte Interamericana y el Tribunal Constitucional del Perú han ampliado el reconocimiento de nuevos grupos en situación de vulnerabilidad como "principio material subyacente" a la consideración de criterios sospechosos respecto de los cuales puede existir discriminación (p. 23).

Ahora bien, los órganos interamericanos de protección derechos humanos se refirieron de manera explícita a determinados grupos en situación de vulnerabilidad en el contexto de la pandemia. Si bien la coincidencia en ambos listados es notable, también se perciben ciertas diferencias.

En ambos listados es posible observar a grupos que han sido tradicionalmente considerados en situación de vulnerabilidad. Sin embargo, también es distinguible la incorporación de grupos respecto de los cuales el desarrollo sobre su identificación de vulnerabilidad, en el sistema interamericano, aún es incipiente como las personas que viven del trabajo informal y en habitación precaria; o respecto de los cuáles existen mayores avances como es el caso en torno a la pobreza, que fue objeto de estudio por parte de la CIDH (2017) y cuyo impacto en los derechos humanos es observado por la Corte IDH, desde hace varios años, con el desarrollo del concepto de "vida digna" a partir del caso Villagrán Morales y otros ("Niños de la calle") vs. Guatemala (1999) según el cual "el derecho de todo ser humano de no ser privado de la vida arbitrariamente, sino también el derecho a que no se le impida el acceso a condiciones que le garanticen una existencia digna" (párrafo 144).

Ahora bien, a partir de las protecciones específicas que se han puesto de relieve desde los órganos de protección de derechos humanos, y la literatura del derecho internacional de los derechos disponible, sobre los grupos vulnerables de cara a la pandemia, es necesario diferenciar aquellas que están relacionadas con las medidas de restricción de derechos para el control de la pandemia, y por otro lado, las protecciones desarrolladas para las personas que padecen 
“¡No mueras, te amo tanto! Pero el cadáver ¡ay! siguió muriendo” : Protecciones específicas, muerte, duelo y derechos humanos en el contexto pandémico

"Do not die, I love you so much! But the corpse, alas! kept on dying": Specific protections, death, bereavement and human rights in the pandemic context

algún tipo de enfermedad desarrollada por el virus SARSCoV2, especialmente la COVID-19. En la siguiente sección, nos referiremos a estas últimas.

\subsubsection{Protecciones específicas para grupos vulnerables} Una lectura en conjunto de estas medidas permite identificar que, en la esfera de protección jurídica de los derechos humanos, los estándares desarrollados por los órganos con mandatos de protección de derechos humanos para la protección de grupos vulnerables pueden ser clasificados del siguiente modo:

(i) estándares relacionados con el acceso a la salud sin discriminación

(ii) estándares relacionados con personas en instituciones totales

(iii) estándares relacionados con la exposición al riesgo de violencia intrafamiliar

(iv) estándares interculturales de protección de derechos humanos

En virtud de lo anterior, el acceso a los tratamientos de salud ha sido una preocupación fundamental de los órganos internacionales de protección de los derechos humanos, focalizado en los derechos de las personas mayores, las personas con discapacidad y personas con enfermedades crónicas (VIH, diabetes, entre otras) y personas cuyo valor social puede ser percibido de modo disminuido sobre la base de prejuicios, como las personas pobres, migrantes y afrodescendientes.

El acceso a tratamientos médicos en función de la disponibilidad de estos y la valoración bioética de cómo se accede a tratamientos en situaciones de saturación de los servicios médicos y escasez de insumos, como apuntó Serrano (2020), genera riesgos de discriminación en la definición de quién tiene prioridad en ser atendido. La determinación de un listado a priori que excluya a personas con peores probabilidades de sobrevivir tiene un impacto diferenciado en el acceso a la salud que debe ser observado de modo sospechoso, especialmente en aquellos criterios que podrían disfrazarse de neutrales, como "la posibilidad de sobrevivir".

En el caso peruano, la Norma técnica para la adecuación del primer nivel de atención en salud durante la epidemia por COVID-19 (2020), de modo preocupante, no establece criterios claros para la atención, más allá de indicar que debe existir una unidad de "triaje" que realicen el análisis clínico de los casos críticos, pese a los lineamientos de la $\mathrm{CIDH}$ en sus resoluciones $1 / 2020$ y 4/2020, como de la Oficina de la Alta Comisionada para los Derechos Humanos de las Naciones Unidas (en adelante "la OACNUDH") en el documento "COVID-19 Guidance" (2020).
Respecto de este último punto, la OACNUDH mostró su preocupación respecto del acceso a servicios de salud de personas en situación migratoria irregular, precisamente porque no son incluidas en los programas de salud, o prefieren no acceder a los mismos por riesgo a ser detenidos, deportados o penalizados.

Otra preocupación común a varios grupos vulnerables, puestas de relieve en el marco de esta pandemia, es la protección de los derechos de personas que se encuentran en instituciones totales, tanto como de cuidado, como los niños, niñas y adolescentes; las personas con discapacidad; los adultos mayores; o en reclusorios en situación de privación de la libertad o detención migratoria. Respecto de las personas en instituciones totales, tanto la OACNUDH y la $\mathrm{CIDH}$, se pronunciaron respecto de la obligación estatal de prevenir los contagios en sitios de cuidado altamente poblados y establecer mecanismos de denuncia ante abusos y malos tratos que pudieran ser cometidos en su contra.

En el caso específico de las personas privadas de la libertad, la CIDH señaló en su Resolución 1/2020 la importancia de los Estados de adoptar medidas para reducir el hacinamiento y evaluar, en los casos de personas en prisión preventiva, el otorgamiento de beneficios carcelarios o medidas alternativas a la privación de la libertad, en los casos que no se vulneren las prohibiciones de otorgar amnistías por crímenes de lesa humanidad o graves vulneraciones a los derechos humanos.

En el caso de personas en situación de movilidad humana, destaca la Resolución de Medidas Urgentes, posteriormente confirmada por la Resolución de Medidas Provisionales del Pleno de la Corte, en la que se requirió al Estado de Panamá que continúe adoptando todas las medidas adecuadas para proteger efectivamente los derechos a la salud, integridad personal y vida de las personas que se encuentran en las Estaciones de Recepción Migratoria La Peñita y Lajas Blancas en la Provincia de Darién, en el marco del cumplimiento de las medidas de no repetición dictadas por la Corte en el caso Vélez Loor Vs. Panamá 
(2020, punto resolutivo 2). En este sentido, aunque pueda discutirse si las medidas provisionales guardaban relación con el objeto de la sentencia y las reparaciones ordenadas por la Corte, el propio órgano jurisdiccional indicó que no es atípico la adopción de medidas provisionales ante condiciones de "particular gravedad" cuando guardan relación con su decisión inicial (párrafo 21).

Respecto de la protección de personas que por las cuarentenas se ven expuestas al abuso y la violencia intrafamiliar, la OACNUDH hizo hincapié en los casos de niñas y mujeres en cuarentena domiciliaria, potencian sus roles como proveedoras de cuidado (care-givers) incrementando sus riesgos de infección. Por su lado, la CIDH resaltó la importancia de fortalecer los servicios de respuesta y denuncia de la violencia basada en género, incluyendo la violencia sexual, en los períodos de confinamiento. En el caso peruano, resulta aterrador que, según la Defensoría del Pueblo, en los primeros 105 días de la pandemia, se interpusieron 400 quejas por violación contra niñas supuestamente cometidas por familiares cercanos, aunque no todos estos casos han conllevado una denuncia penal (2020, p. 8).

Finalmente, es posible observar que los órganos de protección de derechos humanos se han pronunciado respecto de las afectaciones a los derechos de los pueblos indígenas en el contexto de la pandemia. Al respecto, de distingue la importancia puesta sobre el acceso y difusión de información que sea culturalmente accesible y lingüísticamente disponible para atender la realidad de los pueblos indígenas $(\mathrm{CIDH}$, párrafo 54) y respetando sus distintivas nociones de la salud, incluyendo su medicina tradicional, así como la consideración del derecho a la consulta libre, previa e informada en el desarrollo de medidas preventivas en contra del COVID-19 (OACNUDH, p. 8). Es de especial relevancia, en un país como Perú, la directriz trazada por la CIDH respecto de la abstención de la promoción de iniciativas legislativas y proyectos extractivos en territorios indígenas debido a la imposibilidad de llevar a cabo proceso de consulta previa para la disposición de su propiedad sin arriesgar contagios.

Sobre este último punto, resultó sumamente preocupante el anuncio de la reactivación de proyectos de extracción de recursos naturales realizando consultas previas virtuales por parte del Ministerio de Economía. Felizmente, la decisión de llevar a cabo estas "consultas 2.0" fue suspendida. Al respecto, cabe reiterar que la determinación de una metodología virtual para realizar consultas previas, no puede considerarse una medida adecuada si no fue concertada con los pueblos indígenas que serán objeto de la misma. Todo lo contrario, pareciera ser que la mirada de la consulta previa como una "barrera burocrática" no ha sido aún erradicada y, como ha señalado la propia Corte Interamericana, la falta de garantía de los derechos de los pueblos indígenas, no implica solo la desprotección a su propiedad, sino que entraña una mirada discriminatoria de su existencia (2010, párrafos 273-274).

\subsubsection{Personal médico y sanitario y personas con COVID-19}

De otro lado, de modo contextual a la pandemia, es importante resaltar la identificación de grupos en situación de vulnerabilidad al personal médico y sanitario y a las personas con COVID-19. En este sentido, respecto del personal médico, Amnistía Internacional ha puesto de relieve que, a julio de 2020 , cuando menos, más de tres mil trabajadores en salud han perdido la vida en el cumplimiento de la prestación de servicios de salud, muchos más trabajan en entornos peligrosos debido a la falta de equipos de protección y, "han sufrido represalias de las autoridades y de sus entidades empleadoras, incluidos despidos y detenciones, y en algunos casos han sido incluso objeto de violencia y estigma por parte de la población" (2020, p. 5).

En su Declaración 1/20, la Corte Interamericana indicó que el personal médico deberá "ser proveídos de los insumos, equipos, materiales e instrumentos que protejan su integridad, vida y salud, y que les permita desempeñar su labor en términos razonables de seguridad y calidad" (2020). Por su lado la CIDH, también se ha pronunciado respecto de la necesidad de la protección de los derechos laborales de las personas trabajadoras de la salud (descanso, remuneración justa y adecuada, protección de su salud y balance de la sobrecarga laboral) y la obligación estatal de brindarles garantías para que estén libres de hostigamientos y amenazas (2020, párrafo 39).

Sumado a lo anterior, es de especial relevancia que la $\mathrm{CIDH}$ haya emitido una Resolución específica (Res. 4/2020) exclusivamente dirigida al establecimiento de directrices para proteger los derechos de las personas con COVID-19. Esta determinación, permite identificar que el grupo de personas que padecen COVID-19, son un grupo en situación de vulnerabilidad, en el contexto actual de la pandemia.

En este sentido, la CIDH ha establecido directrices en relación con la protección del 
“¡No mueras, te amo tanto! Pero el cadáver jay! siguió muriendo” : Protecciones específicas, muerte, duelo y derechos humanos en el contexto pandémico

"Do not die, I love you so much! But the corpse, alas! kept on dying": Specific protections, death, bereavement and human rights in the pandemic context

derecho a la salud de las personas con COVID-19, partiendo de las obligaciones generales de respeto, garantía y no discriminación, propias de los derechos humanos (párrafo 1) y su derecho a la salud en relación con el acceso a tratamientos, cuidados, medidas paliativas y consentimiento libre, previo e informado del paciente o sus familiares o representantes, cuando el primero no esté en condiciones de hacerlo.

Asimismo, la $\mathrm{CIDH}$ también se ha referido a la prioridad de la vida de las personas con COVID-19 en las políticas públicas, recursos y cooperación para "garantizar el derecho a la vida, a la salud y los programas sociales destinados a apoyar a las personas con COVID-19" (párrafo 25), así como la obligación de regulación del funcionamiento de actores no estatales que prestan servicios de salud, con la finalidad de evitar el desabastecimiento en servicios de salud, garantizando la accesibilidad y asequibilidad de las personas con COVID-19 a tratamientos y cuidados.

Finalmente, la CIDH también determinó directrices en torno a la protección de los derechos laborales (contra el despido injustificado, estabilidad laboral, libertad sindical), el acceso a agua potable, el derecho a la alimentación (adquisición de víveres de primera necesidad), el derecho a la vivienda (adecuación de espacios temporales para habitantes de la calle), el derecho a la educación (adopción de medidas que mitiguen y eviten la interrupción o abandono de estudios) y el acceso a la protección del acceso a la justicia de las personas con COVID-19.

\section{Muerte y derechos humanos en el contexto de la pandemia}

Esta pandemia obliga al Perú a transitar, una vez más, la muerte de modo colectivo. Las escalofriantes imágenes de cadáveres en bolsas negras cuyo único identificador pareciera ser un papel pegado encima de los cuerpos que desbordan los pasillos del Hospital General de Lambayeque o la Morgue Municipal de Loreto nos mostraron los efectos más temidos de la pandemia. Sin embargo, en medio del dolor, es necesario recordar que el Estado debe regular el manejo de cadáveres, de cara a sus obligaciones en materia de derechos humanos, especialmente aquellas relacionadas con el derecho a la identidad, a la integridad y la participación de los familiares en las decisiones sobre el manejo de los restos de sus seres queridos (Vásquez, 2020).

En este sentido, en el marco de esta pandemia, el derecho internacional de los derechos humanos nos obliga a mirar el manejo de los cadáveres desde dos ángulos: la protección de la identidad de los fallecidos y el cuidado del duelo y participación de sus familiares.

\subsection{Las personas fallecidas}

La regulación de la muerte no es ajena a la regulación del derecho internacional de los derechos humanos. En efecto, ante la denuncia de la muerte de una persona a causa de una violación de derechos humanos (por ejemplo una muerte violenta) o de una persona que se encuentra bajo su custodia ya sea un hospital, un cuartel o una prisión (Corte IDH, Caso Quispiayala, 2015, párrafo 115) el Estado tiene la obligación de investigar la muerte de esa persona o, de ser una situación atribuible a su esfera de cuidado, brindar una explicación satisfactoria sobre la muerte de esa persona bajo su custodia a través de una investigación de oficio, seria e imparcial (Corte IDH, Caso Quispiayala, 2015, párrafo 118).

Por otro lado, el DIDH también contiene obligaciones relacionadas con la determinación de la identidad de cadáveres, por ejemplo, que quedan bajo su custodia o que no son reclamados. Así, en el caso de tratarse de una muerte, la Corte IDH ha establecido como parte de la debida diligencia en la investigación criminal, la identificación de la víctima; la determinación de la causa, forma, lugar y momento de la muerte, así como cualquier patrón o práctica que pueda haber causado la muerte; y la distinción entre muerte natural, muerte accidental, suicidio y homicidio (Hermanos Landaeta, 2014, párrafo 227).

De otro lado, el DIDH también ha desarrollado una fuerte regulación relacionada con la desaparición forzada de personas. Según los órganos de protección del sistema interamericano, la desaparición forzada "constituye un hecho ilícito que genera una violación múltiple y continuada de varios derechos protegidos por la Convención Americana y coloca a la víctima en un estado de completa indefensión, acarreando otros delitos conexos" (Corte IDH, párrafo 82). Sin perjuicio de lo anterior, el DIDH, también ha incorporado en su análisis un paso adicional a la prohibición de la desaparición forzada y su definición con una violación pluriofensiva, sino que se están perfilando las obligaciones estatales respecto de la identificación y restitución de restos de las personas desaparecidas que son halladas muertas como ha señalado el Comité contra la Desaparición Forzada de Naciones Unidas en los Principios Rectores para la Búsqueda de Personas Desaparecidas Comité contra 
la Desaparición Forzada (2020, principios 3, 4, 7, 8, 11 y 12).

Sumado a lo anterior, debido a su naturaleza y aplicación material, los tratados sobre derecho internacional humanitario que regulan los conflictos armados, contemplan con mayor precisión los deberes estatales respecto del manejo de restos humanos. En efecto, los Convenios de Ginebra (I, II, III y IV) y sus Protocolos Adicionales (I y II), así como las normas consuetudinarias, contienen prescripciones para el recojo, sin distinción de parte, de cadáveres de las personas que participaron de las hostilidades; el trato debido a los muertos, la identificación de los cadáveres y restitución de los restos a los familiares (Comité Internacional de la Cruz Roja, 2020).

Ahora bien, el manejo y disposición de cuerpos fallecidos por COVID-19, fue regulado en el Perú, en la Directiva Sanitaria 087-2020-DIGESA/MINSA para el manejo de cadáveres por COVID-19, y aunque las prescripciones relativas al manejo de cuerpos fallecidos de personas identificadas es bastante prolija, la Directiva no contiene disposiciones relacionadas con el manejo de los cadáveres de personas no identificadas.

Al respecto, consideramos que desde la aplicación de los normas y estándares de derechos humanos relacionadas con la identificación de personas fallecidas, es posible brindar cobertura a la situación del manejo de cadáveres en la pandemia. En línea con lo anterior, es posible deducir que el Estado tiene la obligación de establecer las medidas necesarias para asegurar el registro documental, forense y/o fotográfico de los de las personas fallecidas por COVID-19 generando su adecuada trazabilidad como ha sido dispuesto, por ejemplo, en el caso mexicano a través de la aprobación del "ACUERDO por el que se prohíbe la incineración de cuerpos no identificados e identificados no reclamados fallecidos a consecuencia de la enfermedad por el virus SARS-CoV2 (COVID-19) y se sugieren medidas para el registro de las defunciones en el marco de la emergencia sanitaria". Dicha normativa, además de la prohibición de incineración de restos no identificados, estableció la obligación de inhumar los cuerpos no reclamados en tumbas individuales o fosas específicas para casos de COVID-19, que facilite su identificación posterior si algún familiar iniciara un proceso de búsqueda posteriormente.

En esta misma línea, es relevante el pronunciamiento de la CIDH, según el cual "(...) reviste especial importancia la prohibición de incineración de los cuerpos sin una adecuada identificación, aun cuando no sean reclamados por sus seres queridos. En tales casos, la $\mathrm{CIDH}$ ha conocido que algunos Estados han prohibido la inhumación de personas fallecidas por COVID-19 en fosas comunes generales y han destinado el uso de fosas específicas para casos sospechosos o confirmados de COVID-19, que posteriormente faciliten su identificación y localización. Lo anterior, en conjunto con un registro detallado e individualizado de personas fallecidas en el contexto de la pandemia" (CP 097/2020).
Finalmente, es necesario recalcar la importancia de que el personal de salud preste especial atención a aquellas supuestas muertes por COVID-19 de personas que se encuentran bajo custodia del Estado o de cuerpos con signos de deceso por la ocurrencia de hechos potencialmente ilícitos. En estos casos, el Estado tiene que actuar conforme a sus obligaciones internacionales y esclarecer las causas de la muerte a través de los estudios médicos y forenses de muertes potencialmente ilícitas como lo establece el Protocolo de Minnesota (2017) en el marco de una investigacion de oficio, seria e imparcial.

\subsection{Los familiares de las personas fallecidas}

En relación con los derechos de los familiares de las personas fallecidas, nuevamente el DIDH ha desarrollado estándares que conviene revisar para proyectar y deducir supuestos de aplicación para la realidad de la pandemia. En estos términos, los estándares internacionales de protección de derechos humanos, han determinado obligaciones en materia de la preservación del duelo, la realizacion de ritos mortuorios y la toma de decisiones sobre sus parientes fallecidos.

La Corte Interamericana ha señalado que el artículo 12 de la $\mathrm{CADH}$, que regula el derecho a la libertad de conciencia y religión, "permite que las personas conserven, cambien, profesen y divulguen su religión o sus creencias. Este derecho es uno de los cimientos de la sociedad democrática. En su dimensión religiosa, constituye un elemento trascendental en la protección de las convicciones de los creyentes y en su forma de vida" (Caso Masacre de Río Negro, párrafo 154). En este sentido, pese a que la Convención Americana no señala expresamente el derecho de enterrar a nuestros muertos, el DIDH permite identificar que esta no es una zona desprovista de protección.

Ahora bien, el análisis realizado por la Corte citado en el párrafo anterior es el aplicado en un caso cuya base fáctica se relaciona con la situación de un pueblo indígena (Caso Comunidad de Río Negro) cuyos miembros fueron ejecutados y desaparecidos, y sus sitios sagrados inundados a raíz de la construcción de una hidroeléctrica, por lo que 
“¡No mueras, te amo tanto! Pero el cadáver ¡ay! siguió muriendo” : Protecciones específicas, muerte, duelo y derechos humanos en el contexto pandémico

"Do not die, I love you so much! But the corpse, alas! kept on dying": Specific protections, death, bereavement and human rights in the pandemic context

se veían impedidos de llevar a cabo ritos fúnebres. Sin perjuicio de lo anterior, y aunque el pronunciamiento de la Corte se dio en el marco del análisis de un caso de derechos indígenas, este razonamiento no nos parece que es excluyente en situación que no involucren a pueblos indígenas, de cara a la protección amplia que brinda el artículo 12 de la $\mathrm{CADH}$.

Sumado a lo anterior, es necesario apuntar que la Corte, en casos relacionados con desaparición forzada, en lo relacionado con medidas de reparación, comúnmente indica que los cuerpos hallados de personas desaparecidas deben ser restituidos dignamente a sus familiares (Caso La Cantuta, 2006, párrafo 232) y que la imposibilidad de enterrar a los muertos incrementa el sufrimiento y angustia de sus familiares (Caso Masacre Plan de Sánchez, 2004, párrafo 87.a). Reafirmando lo anterior, la Corte también ha señalado que (Caso Gomes Lund, 2010, párrafo 261) (...) Recibir los cuerpos de las personas desaparecidas es de suma importancia para sus familiares, ya que les permite sepultarlos de acuerdo a sus creencias, así como cerrar el proceso de duelo que han estado viviendo a lo largo de estos años (...) y que los restos mortales de personas desaparecidas que son halladas muertas "deben ser tratados con respeto para con sus deudos y con el fin de que estos puedan dar una adecuada sepultura (Caso Trujillo Oroza, 2002, párrafo 115).

De otro lado, nos parece importante fijar la atención en relación con los derechos de los familiares de personas desaparecidas en el sistema interamericano y su evolución respecto del modo de participación en los asuntos relacionados con sus parientes víctimas de graves violaciones de derechos humanos. En este sentido, en la participación de las víctimas ha sido abordada a partir de su posibilidad de constituirse como parte procesal en el marco de las investigaciones para el enjuiciamiento y sanción de los responsables, reivindicando con dicha participación su derecho a conocer la verdad (Caso Mapiripán, 2005, párrafos 219, 297).

Sumado a lo anterior, este derecho de participación también ha sido aplicado a otros ámbitos de las acciones estatales orientadas a la reparación de los derechos de los familiares de personas que han sido afectadas por graves violaciones, incorporando este componente a través de la obligación de tomar en consideración a los familiares en determinadas políticas de reparación de tipo no judicial. En estos términos, en casos en los que ha dispuesto la creación de órganos para abordar asuntos relacionados con desaparición forzada como medidas de reparación, la Corte ha señalado que este tipo de órganos debe asegurar la participación de los familiares (Caso Hermanas Serrano Cruz, 2005, párrafo 188) y que los operativos de búsqueda de personas desaparecidas e identificación de restos deben basarse en "en directrices y protocolos sobre la materia, incluyendo lo que respecta a comunicación y acción coordinada con los familiares de los desaparecidos" (Caso Gomes Lund, 2014, párrafo 35).
Tras la revisión de los estándares anteriormente citados, podemos observar que el DIDH se ha abierto campo en la regulación de los temas relacionados con el duelo y la celebración de ritos mortuorios. $Y$ como hemos señalado, al margen de la base fáctica en la que la Corte IDH aplicó dichos casos, esto no es óbice para entender que la protección del artículo 16 de la CADH puede ser aplicada en el contexto de la pandemia, sin necesidad de un esfuerzo interpretativo excesivo.

Ahora bien, respecto de los estándares relacionados con la participación de los familiares de personas que han sufrido graves violaciones de derechos es posible observar que estos están dirigidos a la búsqueda de personas desaparecidas o a su participación de procesos judiciales en virtud de sus derecho de acceso a la justicia protegido convencionalmente en el artículo 25 de la $\mathrm{CADH}$. Encontramos que estos supuestos de aplicación no pueden ser forzados al grado que nos permita afirmar, mutatis mutandis, que son aplicables a la situación de la pandemia en relación con la participación de los familiares en las decisiones relacionadas con la disposición de los cuerpos de sus seres queridos fallecidos.

Sin perjuicio de lo anterior, los estándares anteriormente mencionados, sí nos permite observar que la Corte IDH otorga un rol a los familiares en la determinación de la situación jurídica de sus seres queridos en el plano jurídico internacional, lo que no es poca cosa, desde un punto de vista humanitario.

Ahora bien, de cara a la situación de la pandemia, es necesario regresar a la Directiva Sanitaria 087-2020-DIGESA/MINSA aprobada para el manejo de cadáveres fallecidos por COVID-19. Dicha Directiva "prohíbe los velorios, pues evidentemente dicha práctica rompería el distanciamiento social ordenado por el estado de emergencia. Sin embargo, dicha restricción debe ser compatibilizada con los derechos mencionados y tomar en consideración contextos culturales, por ejemplo indígenas, o religiosos que pueden ser llevados a cabo respetando las reglas del distanciamiento social y las salvaguardas dispuestas en 
la declaratoria del estado de emergencia, para que no se conviertan restricciones arbitrarias".

Como la CIDH (2020), en su comunicado de prensa No 097/20 ha señalado, "la preservación de la memoria y de homenaje a las personas fallecidas, cuyo trato digno es inherente a su condición humana y esencial en respeto a los vínculos y lazos existentes entre sus familiares y personas más cercanas". En esta línea, la CIDH (2020) también ha señalado que las dificultades de los familiares para enterrar a sus muertos es un hecho que impacta en su derecho a la integridad personal, pues ocasiona angustia y un mayor sufrimiento dado que "sepultar a los familiares fallecidos de acuerdo con sus creencias, aporta un cierto grado de cierre al proceso de duelo, contribuyendo a mitigar las secuelas del trauma, luto y dolor" (comunicado de prensa 097/20).

Asimismo, la CIDH (2020), en el comunicado de prensa 097/20, también ha resaltado lo siguiente: "las dificultades que tienen los familiares para enterrar a sus muertos es un hecho que impacta en su derecho a la integridad personal, ocasionando angustia y un mayor sufrimiento. La Comisión ha considerado que la posibilidad de sepultar a los familiares fallecidos de acuerdo a sus creencias, aporta un cierto grado de cierre al proceso de duelo, contribuyendo a mitigar las secuelas del trauma, luto y dolor".

Finalmente, respecto de la partipación de familiares, la regulación comentada incorpora la participación de un "pariente directo" en la decisión sobre la disposición de los restos de su ser querido. La incorporación de un pariente en esta situación, nos parece que resulta consonante con los estándares mencionados anteriormente sobre la participación de familiares en los asuntos de sus seres queridos y respecto del hecho de otorgarles un rol participativo a los familiares en la toma de decisiones sobre los cuerpos de sus familiares fallecidos.

Sin embargo, es necesario observar con atención que la denominación de "pariente directo" para la decisión de inhumación o incineración del cuerpo de la persona fallecida es una limitación para familias conformadas por parejas del mismo sexo quienes, en Perú, no gozan de ningún tipo de reconocimiento. Una solución más inclusiva, hubiera resultado en la disposición de que las decisiones médicas y de disposición del cadáver recaigan en la persona que el paciente designó en vida y no necesariamente en su familia consanguínea, dado que en muchos casos de personas LGBTIQ dicho contexto representa un espacio de violencia y es el entorno social su verdadera red de apoyo familiar.

\section{Conclusiones}

El efecto disruptivo de la pandemia, desde una mirada del DIDH, nos obliga a mirar las medidas de control epidémico y sus efectos, poniendo como centro y en primer lugar al ser humano, como sujeto de derecho de protección internacional. Al repasar las restricciones y confrontarlas con las protecciones, hemos podido observar que los estándares de derechos humanos permiten deducir protecciones generales y específicas.

De modo general, el DIDH impone límites a las medidas provenidas de la adopción del estado de emergencia, estableciendo criterios para su establecimiento válido y controlado. De otro lado, el DIDH también presta atención al impacto diferenciado que estas medidas puedan generar respecto de grupos en situación de vulnerabilidad, especialmente en lo relacionado al acceso sin discriminación a tratamiento y cuidados en salud, la protección de las personas en instituciones totales, el impacto en términos sexo-genéricos frente a las medidas de confinamiento y el despliegue de medidas interculturales para atender las realidades indígenas.

Asimismo, la maleabilidad del DIDH también permite observar el despliegue de protecciones respecto de situaciones incluso más atípicas, como las obligaciones sobre la identificación de los cadáveres, el descarte de muertes violentas, la prohibición de incineraciones de cuerpos no reclamados, y la generación de evidencia para la trazabilidad de la identidad de los fallecidos en caso de que un familiar decida emprender un proceso de búsqueda. Así también, hemos deducido que los familiares mantienen protegidos sus derechos a la información sobre sus familiares fallecidos, su derecho al duelo y realizar ritos mortuorios y el rol relevante respecto de las decisiones sobre sus seres queridos fallecidos.

Antes de concluir, es necesario apuntar un tema ausente en el presente artículo, y es el derecho a la integridad en su faceta relacionada con la salud mental. El trauma social acompañará a la sociedad peruana por un tiempo, y mientras se hacen las sumas y restas de los y las que se fueron, y todo lo perdido, es necesario que el Estado emprenda también los esfuerzos en la recomposición psicosocial colectiva y despliegue los mecanismos adecuados para 
“¡No mueras, te amo tanto! Pero el cadáver ¡ay! siguió muriendo” : Protecciones específicas, muerte, duelo y derechos humanos en el contexto pandémico

"Do not die, I love you so much! But the corpse, alas! kept on dying": Specific protections, death, bereavement and human rights in the pandemic context

crear las condiciones de acceso a la atención psicológica individual. Tal vez, el esfuerzo de implementar la feliz idea del aseguramiento universal pueda comenzar por esto, pues, al final, en el poema de Vallejo que titula este artículo, el soldado se levantó y comenzó a andar.

\section{Referencias bibliográficas}

Amnistía Internacional. (2020). Expuesto, acallado y atacado, deficiencias en la protección del personal sanitario y que realiza labores esenciales durante la pandemia de COVID-19. Amnesty International 2020, 1-63. https://amnistia.org.mx/contenido/wp-content/ uploads/2020/07/Health-and-Essential-Workers-report_ES.pdf

Aniyar, L. (1989). Los muertos de la democracia: proyecto autoritario de la democracia y sus efectos generadores de represividad en las representaciones sociales. Revista Capítulo Criminológico, número 17, 58-71. https://produccioncientificaluz.org/index.php/capitulo/article/ view/4065

Asociación Peruana de Derecho Constitucional. (2020). Emergencia sanitaria por COVID 19. Retos al constitucionalismo peruano. En E. Curaca, Estados de excepción en época de pandemia una breve mirada a la jurisprudencia constitucional y a la declaratoria del estado de emergencia (pp. 23-32). Adrus \& DL Editores.

Comisión Interamericana de Derechos Humanos. (1998, 4 de junio). Demanda de la CIDH presentada ante la Corte IDH en el caso de la comunidad indígena Mayagna (Sumo) de Awas Tingni.

Comisión Interamericana de Derechos Humanos. (2017, 7 de septiembre). Informe sobre pobreza y derechos humanos en las Américas. http://www.oas.org/es/cidh/informes/pdfs/ PobrezaDDHH2017.pdf

Comisión Interamericana de Derechos Humanos. (2020, 10 de abril). Resolución 1/2020 Pandemia y Derechos Humanos en las Américas. https://www.oas.org/es/cidh/decisiones/pdf/Resolucion-1-20-es.pdf

Comisión Interamericana de Derechos Humanos. (2020, 1 de mayo). Respeto al duelo de las familias de las personas fallecidas en la Pandemia del COVID19. https://www.oas.org/es/cidh/prensa/ comunicados/2020/097.asp

Comisión Interamericana de Derechos Humanos. (2020, 27 de julio). Resolución 4/2020 Derechos Humanos de las personas con COVID-19. https://www.oas.org/es/cidh/decisiones/pdf/Resolucion-4-20-es.pdf

Comité Internacional de la Cruz Roja. (2020, 3 de abril). Humanidad después de la vida: respecto y protección de las personas fallecidas. https://www.icrc.org/es/document/humanidad-despues-de-la-vidarespeto-y-proteccion-de-las-personas-fallecidas

Corte Interamericana de Derechos Humanos. (1987, 30 de enero). Opinión Consultiva OC-8/87 El hábeas corpus bajo suspensión de garantías (Arts. 27.2, 25.1 y 7.6 Convención Americana sobre Derechos Humanos). https://www.corteidh.or.cr/docs/opiniones/seriea_08_esp. pdf

Corte Interamericana de Derechos Humanos. (1987, 6 de octubre). Opinión Consultiva OC-9/87 Garantías judiciales en Estados de Emergencia (Arts. 27.2, 25 y 8 Convención Americana sobre Derechos Humanos). https://www.corteidh.or.cr/docs/opiniones/seriea_09_esp. pdf
Corte Interamericana de Derechos Humanos. (1999, 19 de noviembre). Caso de los "Niños de la Calle" (Villagrán Morales y otros) vs. Guatemala. https://www.corteidh.or.cr/docs/casos/articulos/ Seriec_63_esp.pdf

Corte Interamericana de Derechos Humanos. (2002, 27 de febrero). Caso Trujillo Oroza Vs. Bolivia. https://www.corteidh.or.cr/docs/casos/ articulos/Seriec_92_esp.pdf

Corte Interamericana de Derechos Humanos. (2004, 19 de noviembre). Caso Masacre Plan de Sánchez Vs. Guatemala (Reparaciones). https://www.corteidh.or.cr/docs/casos/articulos/ seriec_116_esp.pdf

Corte Interamericana de Derechos Humanos. (2005, 1 de marzo). Caso de las Hermanas Serrano Cruz Vs. El Salvador. https://www.corteidh.or.cr/ docs/casos/articulos/seriec_120_esp.pdf

Corte Interamericana de Derechos Humanos. (2005, 15 de septiembre). Caso de la "Masacre de Mapiripán" Vs. Colombia. https://www.corteidh. or.cr/docs/casos/articulos/seriec_134_esp.pdf

Corte Interamericana de Derechos Humanos. (2006, 22 de septiembre). Caso Goiburú y otros Vs. Paraguay. https://www.corteidh.or.cr/docs/casos/ articulos/seriec_153_esp.pdf

Corte Interamericana de Derechos Humanos. (2006, 29 de noviembre). Caso La Cantuta Vs. Perú. https://www.corteidh.or.cr/docs/casos/ articulos/seriec_162_esp.pdf

Corte Interamericana de Derechos Humanos. (2010, 24 de agosto). Caso Comunidad Indígena Xákmok Kásek Vs. Paraguay. https://www.corteidh. or.cr/docs/casos/articulos/seriec_214_esp.pdf

Corte Interamericana de Derechos Humanos. (2010, 24 de noviembre). Caso Gomes Lund y otros ("Guerrilha do Araguaia") Vs. Brasil. https://www.corteidh.or.cr/docs/casos/articulos/ seriec_219_esp.pdf

Corte Interamericana de Derechos Humanos. (2014, 27 de agosto). Caso Hermanos Landaeta Mejías y otros Vs. Venezuela. https://corteidh.or.cr/ docs/casos/articulos/seriec_281_esp.pdf

Corte Interamericana de Derechos Humanos. (2014, 17 de octubre). Caso Gomes Lund y otros ("Guerrilha do Araguaia") Vs. Brasil Supervisión de Cumplimiento de Sentencia. https://www.corteidh. or.cr/docs/supervisiones/gomes_17_10_14.pdf

Corte Interamericana de Derechos Humanos. (2015, 23 de noviembre). Caso Quispialaya Vilcapoma Vs. Perú. https://www.corteidh.or.cr/ docs/casos/articulos/seriec_308_esp.pdf

Corte Interamericana de Derechos Humanos. (2020, 9 de abril). Declaración de la Corte 
Interamericana de Derechos Humanos 1/20, COVID-19 y derechos humanos: los problemas y desafíos deben ser abordados con perspectiva de derechos humanos y respetando las obligaciones internacionales. https://www.corteidh.or.cr/tablas/alerta/comunicado/ declaracion_1_20_ESP.pdf

Corte Interamericana de Derechos Humanos. (2020, 29 de julio). Resolución de Adopción de Medidas Provisionales, Caso Vélez Loor vs. Panamá de 29 de julio de 2020. https://www.corteidh.or.cr/docs/ medidas/velez_se_02.pdf

Defensoría del Pueblo. (2020). Prevención y gestión de conflictos sociales en el contexto de la pandemia por el COVID-19 (Serie Informes Especiales N 026-2020-DP). https://www.defensoria.gob. pe/wp-content/uploads/2020/07/Informe-Especial-026-2020-DPPrevenci\%C3\%B3n-y-Gesti\%C3\%B3n-de-conflictos-APCSG.pdf

Defensoría del Pueblo. (2020). Problemática en la atención de casos de violación sexual de niñas, niños y adolescentes en el contexto de la emergencia sanitaria por COVID-19 (Serie Informes Especiales $\mathrm{N}^{\circ}$ 021-20202-DP). https://www.defensoria.gob.pe/wp-content/ uploads/2020/07/Serie-Informes-Especiales-N\%C2\%BA-021-2020DP.pdf

Diario Oficial de la Federación. (2020, 17 de abril). Acuerdo por el que se prohíbe la incineración de cuerpos no identificados e identificados no reclamados fallecidos a consecuencia de la enfermedad por el virus SARS-CoV2 (COVID-19) y se sugieren medidas para el registro de las defunciones en el marco de la emergencia sanitaria. https://www. dof.gob.mx/nota_detalle.php?codigo $=5591880 \&$ fecha $=17 / 04 / 2020$

Faúndez, H. (2004). El sistema interamericano de protección de los derechos humanos, aspectos institucionales y procesales (3. ${ }^{\text {a }}$ ed.). Instituto Interamericano de Derechos Humanos. https://www.iidh.ed.cr/ IIDH/media/1575/si_proteccion_ddhh_3e.pdf

García, S. (2019). Los sujetos vulnerables en la jurisprudencia "transformadora" de la Corte Interamericana de Derechos Humanos. Cuestiones Constitucionales: Revista Mexicana de Derecho Constitucional, número 41, 3-34. http://doi.org/10.22201/ iij.24484881e.2019.41.13940

Grupo de Análisis de Datos sobre Derechos Humanos de la American Association for the Advancement of Science para la Comisión de la Verdad y Reconciliación. (2003). Anexo 2. ¿Cuántos peruanos murieron? Estimación del total de víctimas causadas por el conflicto armado interno entre 1980 y el 2000. http://www.cverdad.org.pe/ifinal/ pdf/Tomo\%20-\%20ANEXOS/ANEXO\%202.pdf

Landa, C. (2020). Constitucionalismo de emergencia frente al Coronavirus en el Perú. En Constitución y emergencia sanitaria (pp. 15-25). Palestra.

Lovatón, D. (2020). Aislamiento social obligatorio, estado de emergencia, fuerzas del orden y pandemia en el Perú. DPLF. http:// dplf.org/sites/default/files/peru_david_lovaton.pdf

Lovatón, D. (2020, 6 de abril). América Latina: Derechos civiles y políticos en tiempos de pandemia. Justicia en las Américas: Blog de la Fundación para el Debido Proceso. https://dplfblog.com/2020/04/06/ america-latina-derechos-civiles-y-politicos-en-tiempos-de-pandemia/

Maguiña, C. (2020). Reflexiones sobre el COVID-19, el Colegio Médico del Perú y la Salud Pública. Acta Médica Peruana, 37(1), 8-10. http:// dx.doi.org/10.35663/amp.2020.371.929
Ministerio de Salud. (2020). Directiva Sanitaria $N^{\circ}$ 087-2020-DIGESA/MINSA. http://www. digesa.minsa.gob.pe/Orientacion/DIRECTIVA SANITARIA_087-2020-DIGESA-MINSA PARA_EL_MĀNEJO_DE_CADAVERES_POR_ COVID_19_CONSOLIDADO_ACTUALIZADO.pdf

Ministerio de Salud. (2020, 22 de mayo). Resolución Ministerial N³09-2020. https://cdn.www.gob.pe/ uploads/document/file/729861/RM_309-2020MINSA.PDF

Oficina del Alto Comisionado de las Naciones Unidas para los Derechos Humanos. (2017). Protocolo de Minnesota sobre la investigación de muertes potencialmente ilícitas (2016). Nueva York y Ginebra. https://www.ohchr.org/Documents/ Publications/MinnesotaProtocol_SP.pdf

Oficina del Alto Comisionado de las Naciones Unidas para los Derechos Humanos. (2020, 13 de mayo). COVID-19 Guidance. https://www.ohchr. org/Documents/Events/COVID-19_Guidance.pdf

Organización Panamericana de Salud. (2019, 13 de diciembre). OPS felicita y ofrece apoyo al Perú para la implementación de la Cobertura Universal en Salud. https://www.paho.org/per/index.php?option=com content\&view =article\&id=4443:ops-felicita-yofrece-apoyo-al-peru-para-la-implementacion-dela-cobertura-universal-en-salud\&Itemid=

Presidencia de la República. (2020, 15 de marzo). Decreto Supremo 044-2020-PCM. https://cdn. www.gob.pe/uploads/document/file/566448/ DS044-PCM_1864948-2.pdf

Presidencia de la República. (2020, 26 de junio). Decreto Supremo 116-2020-PCM. https://cdn.www. gob.pe/uploads/document/file/898487/DS_1162020-PCM.pdf

Presidencia de la República. (2019, 28 de noviembre). Decreto de Urgencia 017-2019. https://cdn.www.gob.pe/uploads/document/ file/431389/1831446-1.pdf

Presidencia de la República. (2020, 28 de agosto). Decreto Supremo 146-2020-PCM. https://cdn. www.gob.pe/uploads/document/file/1322659/ DS\%20N\%C2\%B0\%20146-2020-PCM.pdf

Salmón, E. (2014). Curso de Derecho Internacional Público. Fondo Editorial PUCP.

Serrano, S. (2020, 15 de mayo). Sobre la obligación de prevenir y anticipar el racionamiento de la terapia intensiva en el contexto de COVID-19 y los riesgos de discriminación. Revista Derecho del Estado. https://revistaderechoestado.uexternado. edu.co/2020/05/15/sobre-la-obligacionde-prevenir-y-anticipar-el-racionamientode-la-terapia-intensiva-en-el-contexto-deCOVID-19-y-los-riesgos-de-discriminacion/?- 
“¡No mueras, te amo tanto! Pero el cadáver ¡ay! siguió muriendo” : Protecciones específicas, muerte, duelo y derechos humanos en el contexto pandémico

"Do not die, I love you so much! But the corpse, alas! kept on dying": Specific protections, death, bereavement

and human rights in the pandemic context

fbclid=IwAR0sVnb92xB8ajZ1evuVI7j6y0uCEdNU a69CJfKnOYO0X40hNq9b8HhXuCk

Sonnleitner, L. (2019). The democratic legitimacy of evolutive interpretation by the European Court of Human Rights. Temple International \& Comparative Law Journal, 33(2), 279-297. https://sites.temple. edu/ticlj/files/2019/09/33.2_Sonnleitner_Article3. pdf

Taj, M. \& Kurmanaev, A. (2020, 12 de junio). El virus exhibe las debilidades de la historia de éxito de Perú. The New York Times. https://www.nytimes. com/es/2020/06/12/espanol/america-latina/perucoronavirus-corrupcion-muertes.html

Torp, S. (2013). Evolutive Treaty Interpretations:
Legality, Semantics and Distinctions. European Journal of Legal Studies, 6(1), 127-148. https://cadmus.eui.eu/handle/1814/28733

Tribunal Constitucional del Perú. (2004, 16 de marzo). Sentencia del EXP. N. ${ }^{\circ}$ 0017-2003-Al/TC. https://www.tc.gob.pe/ jurisprudencia/2004/00017-2003-Al.html

Valdivia, T. (2020). ¿Sospechar para igualar? Un análisis "estricto" de la doctrina de las categorías sospechosas a partir de la jurisprudencia del Tribunal Constitucional peruano y la Corte Interamericana de Derechos Humanos. Derecho PUCP, número 84, 9-87. https://doi. org/10.18800/derechopucp.202001.001

Vásquez, P. (2020, 26 de mayo). ¿A dónde van los cuerpos de los que no se quedaron?. El Comercio. https://elcomercio.pe/opinion/ colaboradores/a-donde-van-los-cuerpos-de-los-que-no-se-quedaronpor-piero-vasquez-aguero-noticia/ 